\title{
Monitoring of Biodiesel Transesterification Process Using Impedance Measurement
}

\author{
T. Rachmanto, D. Allanson, C. Matthews, and I. Jenkinson
}

\begin{abstract}
Transesterification is commonly used to produce biodiesel from methylester. In order to control the conversion process it is often useful to employ process monitoring and in particular monitor the mass transfer processes that limit the initial reaction rates. Such monitoring of the initial phase of reaction may provide opportunity for process optimization. Previous work has identified many methods to monitor reaction progress. This paper proposes the use of a simple method which is able to provide information regarding the progress of mass transfer and chemical reaction during biodiesel production. The process uses impedance measurement. The experimentally determined impedance results clearly show the two important phases of the transesterification reaction, a mass transfer control phase followed by a kinetically controlled phase.
\end{abstract}

Index Terms-Biodiesel, impedance, interdigital impedance sensor, transesterification, process monitoring.

\section{INTRODUCTION}

Alternative diesel fuels have been the subject of extensive investigation. The consumption of mineral based Diesel fuels is increasing significantly together with the associated problems of environmental damage. Fatty acid methyl ester (FAME) based Biodiesel manufactured from vegetable oils or animal fats is excellent candidate to replace common diesel fuel being renewable, non-toxic and often giving rise to reduced exhaust gas emission (lower levels of nitrogen oxide (NOx) emissions). Unfortunately vegetable oils cannot be simply used to fuel diesel engine due to its increased viscosity and lower volatility (tendency of a compound to vaporize) [1].

Biodiesels are commonly derived by converting triglycerides (vegetable oils or animal fats) to alkyl esters. The resulting alternative diesel fuel suffers from the disadvantage of having viscosity around 10 to 17 times greater than that of ordinary diesel [2]. Consequently it is difficult to utilize the renewable based fuel directly in a diesel engine designed for operation with mineral Diesel. Operation with the alkyl ester based fuel can lead to increased carbon deposits, injectors coking, oil ring sticking and the possibility of lubrication oil degradation caused by contamination with vegetable oil [3].

Several techniques have been investigated to reduce the viscosity of vegetable oils and fats in order to meet diesel fuel standards. Transesterification is a widely used method for the production of biodiesel and is the subject of significant

Manuscript received February 5, 2014; revised March 31, 2014.

T. Rachmanto, D. Allanson, and C. Matthews are with the School of Engineering, Liverpool John Moores University, UK (e-mail: t.rachmanto@gmail.com).

I. Jenkinson is with the School of Engineering Technology and Marine Operations Liverpool John Moores University, UK. research effort. The transesterification process can be performed in both batch and continuous reactors. In the batch reaction the process is highly influence by factors such as stirring speed, molar ratio, catalyst and temperature. In order to optimize the biodiesel transesterification process, on line monitoring is required to provide feedback for system control. Feedback is required to indicate whether the process has reached steady state conditions and delivers the opportunity to save energy during the process by reducing mechanical agitation or by reduction of heater input energy [4].

Gas chromatography (GC) has been used to characterize the biodiesel properties during the reaction process, high precision GC measurement can be used to determine product yield (methyl esters) and conversion efficiency. However gas chromatography is not typically used for online measurement as it requires intensive sample preparation and the cost of the equipment is prohibitive and is unsuitable for low cost industrial process monitoring and control purposes.

Alternative measurement/monitoring approaches have been investigated. The use of a fibreoptic probe based on Near Infra Red (NIR) spectroscopy to monitor the transesterification process was investigated by Knothe [5]. Ellis et al. [6] investigated the use of an acoustic wave solid state viscometer to measure shear stress during the transesterification reaction and presented results showing that the shear stress and hence viscosity dropped significantly during the reaction process before reaching a steady state value. Trevisan also investigated the use of infrared spectroscopy to monitor a batch biodiesel reaction [7], DeBoni employed laser spectroscopy to monitor the transesterification process over a period of 6000s. His results indicated that a steady state was achieved after 2500 seconds [8]. The identified prior work has proven that it is possible to use simple methods to monitor the transesterification process and determine state of the reaction during the region controlled by the chemical reaction kinetics and that it may be possible to employ sensors for feedback control purposes.

\section{TRANSESTERIFICATION}

A number of sequence and reversible reactions are occurring during the biodiesel transesterification process. Triglycerides and free fatty acid (oil or vegetable oils) will undergo a reversible reaction with an alcohol, the products of this reaction are glycerol (GL) and fatty (FA) acid alkyl ester. Monoglycerids (MG) and diglycerids (DG) are formed during the reactions of catalytic transesterification reactions to glycerol and methyl ester as final products. The triglycerides can be converted with or without the use of a catalyst, however alkali or acid catalyze is commonly used for commercial applications. A catalyst free reaction can be 
performed under certain circumstance such as on the critical condition.. A batch transesterification process has two significant mechanisms, and exhibits a mass transfer control region that is followed by a second order kinetically controlled region [9].
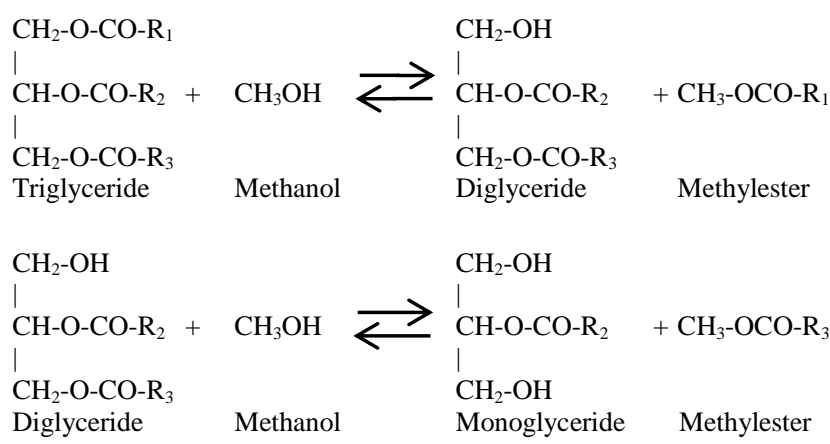

\begin{tabular}{|c|c|c|c|}
\hline $\mathrm{CH}_{2}-\mathrm{OH}$ & & $\mathrm{CH}_{2}-\mathrm{OH}$ & \\
\hline $\mathrm{CH}-\mathrm{O}-\mathrm{CO}-\mathrm{R}_{2}+$ & $\mathrm{CH}_{3} \mathrm{OH}$ & $\mathrm{CH}-\mathrm{OH}$ & $+\mathrm{CH}_{3}-\mathrm{OCO}-\mathrm{R}_{3}$ \\
\hline $\begin{array}{l}\mathrm{CH}_{2}-\mathrm{OH} \\
\text { Monoglyceride }\end{array}$ & Methanol & $\begin{array}{l}\mathrm{CH}_{2}-\mathrm{OH} \\
\text { Glycerol }\end{array}$ & Methylester \\
\hline
\end{tabular}

\section{MASS TRANSFER AND REACTION}

In the early stages of the transesterification process the methanol is ineffective as the rate of reaction is limited by the interface mass transfer resistance [10]. This is due to the reactants being initially, in effect unmixed. Subsequent agitation of the reactants causes mixing, increasing the interfacial area and reducing the interface mass transfer resistance. The time required to bring about the required degree of mixing gives rise to a significant time delay between methanol and catalyst injection and the start of any significant transesterification reaction. As a result the transesterification process can be divided into two regimes, the regime controlled by the mass transfer process (methanol injection and reactant mixing) and the regime where the process is controlled by the reaction kinetics.

The ability to monitor progression through the two regimes may provide opportunities for the development of strategies for automatic control and optimisation. For this purpose it may be beneficial to determine the extent of mass transfer, detect the completion of mass transfer, detect the start of significant reaction and subsequently determine the point of completion. For continuous flow reactors determination of mixing effectiveness and reaction completeness may also be off significant benefit for control purposes.

The influence of mass transfer on the transesterification process may be mostly dependent on controlling variables such as impeller type/number, agitation speed, agitation amplitude and reaction temperature. Previous work has identified agitation methods such as the use of magnetic stirrer, static stirrer, ultrasound and ultra turrax. Bambase et al. [11] reported that the using of a higher agitation speed (magnetic stirrer) reduces the mass transfer resistant significantly. For the transesterification of crude sunflower oil it was shown that the mass transfer limitation was reduced to an effective zero time lag by selecting a 400-600 rev/min agitation speed. Other researchers [12], [13] have revealed that mass transfer coefficients achieved for the transesterification process using mechanical agitation with the mixing rate of $700 \mathrm{~min}-1$ is 10.3 times higher than that reported with 100 min-1 mixing rate. In addition the use of a higher reaction temperature can reduce mass transfer limitations with the higher energy level of molecules resulting faster diffusion into a pseudo homogeneous phase [14]. This previous work has shown that there is potential to optimise mechanical agitation and minimise the effects of mass transfer resistance during the batch reaction of biodiesel. Such optimisation should lead to increased process efficiency, reduced reaction time, reduced energy consumption and better utilisation of the reactants. This can be achieved by utilising a relatively simple design of sensor together with strategies for closed loop process control.

\section{INTERDIGITAL IMPEDANCE SENSOR}

The authors have identified a need to develop a cost effective sensing strategy that would allow for the closed loop control of simple batch and continuous flow reactors. The sensor developed is based on the InterDigital (ID) design that has been successfully employed in other fields, such as the estimation of the nitrate contaminantion [15] and to sense the presence of dangerous marine biotoxins in seafood as developed by Sayifudin et al. [16]. ID sensors have also been developed and employed biomedical applications [17].

The ID sensor is of simple construction and consists of two sets of interleaved electrodes (fingers). The two sets of electrodes are separated by a gap and when an AC excitation voltage is applied across the interleaved electrodes an oscillating electric field is developed.

The fields generated by the excitation will penetrate into the material surrounding the sensor, in this case the reacting fluids. The dielectric properties (permittivity) of the material surrounding the sensor will therefore have a significant influence on how the material interacts with an applied electromagnetic field. Hence the dielectric properties in conjunction with electrode and substrate geometry will directly affect the capacitance and the conductance of the electrodes [18]. If the electrodes are insulated from the material under test, then the sensor will detect purely changes in capacitance. Alternatively if the electrodes are directly in contact with the material under test (as in this application) then the sensor will detect changes in capacitance and electrical conductivity of the material under test. This will make the sensor simultaneously sensitive to changes in ion concentration and dielectric properties allowing the sensor to detect the changes resulting from the mixing of reactants during the mass transfer and the change in dielectric properties resulting from transesterification.

When a sinusoidal voltage is applied across the electrodes of a planar ID sensor, the current flow between the electrodes is the result of the applied potential difference and described by Ohms law. The ratio between the excitation voltage and the resulting current flow is the impedance $(Z)$.

The impedance is a complex quantity and ignoring the effects of parasitic inductance, we can consider it to consist of two phasor components, the resistance (ZR) or real part and the capacitive reactance $(\mathrm{ZC})$ or imaginary part.

$$
Z=Z^{\prime}+j Z^{\prime \prime}
$$


The capacitive reactance is perpendicular to the resistance and hence the sensor current will be out of phase with the excitation voltage by the angle $\theta$ that depends on the relative magnitude of the two effects.

$$
\theta=\tan ^{-1}\left(\frac{Z^{\prime \prime}}{Z^{\prime}}\right)
$$

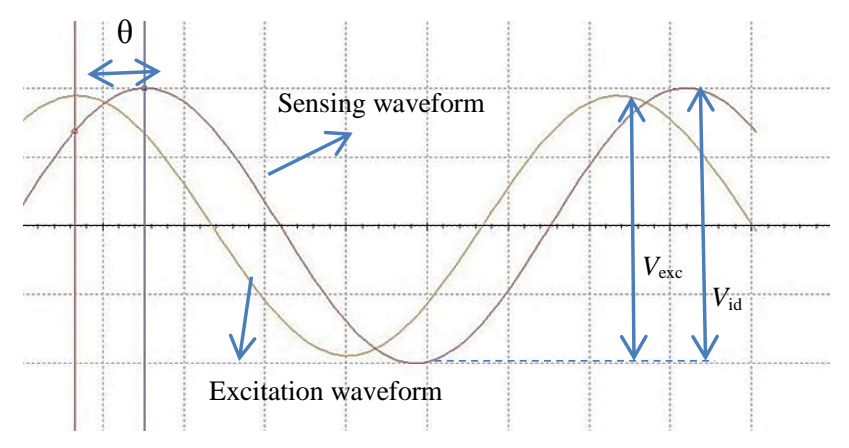

Fig. 1. Relationship between the applied voltage and induced current in an impedance measurement.

The capacitive reactance is mainly affected by frequency of excitation $f$ and the capacitance $C$ between the electrodes.

$$
Z^{\prime}=\frac{1}{2 \pi f C}
$$

The capacitance between the electrodes depends upon the geometry of the sensor and the dielectric properties of the substrate and surrounding material. For a simple capacitor comprising of two parallel circular plates the capacitance is given by:

$$
C=\varepsilon \frac{A}{D}
$$

where $\varepsilon$ is the complex permittivity in $\mathrm{F} / \mathrm{m}, A$ is the effective area of the plates and $D$ is the interplate distance. Complex permittivity is complex parameter and consists of real and imaginary parts. The real part is representing the value of material polarization and the imaginary part is representing value caused by ohmic and polarization losses. If losses come from the migration of charge carriers complex permittivity can be written:

$$
\varepsilon=\varepsilon^{\prime}-j \varepsilon^{\prime},
$$

where $\varepsilon=$ complex permittivity; $\varepsilon^{\prime}=$ real part of permittivity; $\varepsilon "=$ imaginary part of permittivity; and $j=\sqrt{-1}$. For medium having high conductivity the effect of charge migration cannot be simply neglected, the permittivity or dielectric constant is then given by [19]:

$$
\varepsilon=\varepsilon^{\prime}\left(1-\frac{j \sigma}{\omega \varepsilon \prime}\right)
$$

where $\sigma$ is the conductivity of the liquid, the loss tangent is $\frac{j \sigma}{\omega \varepsilon \prime}$ and represents the ratio of conductive current to displacement current in the material. The materials have low loss if loss tangent less than 0.1 and material has high loss if the loss tangent is greater than 10 [19]. Perfect dielectric material does not possess a conductivity value, it can hold and returns a charge from electromagnetic energy.
Assuming that the ID sensor behaves in a similar manner to the simple plate capacitor, then for a given frequency of excitation and fixed sensor geometry, the capacitance will depend solely on the dielectric constant and changes in the material composition will directly give rise to a change in the measured value of $Z$ '. During the initial stages of transesterification the reactants are effectively unmixed and the conductivity measured by the sensor will represent that of the raw feedstock. During methoxide injection and mixing, the conductivity will be expected to increase as the ions are distributed throughout the reactant volume increasing its conductivity. As mass transfer near completion chemical reactions begin, both real part and imaginary parts of the liquids dielectric will be simultaneously changing. Increasing liquid conductivity due to enhance ion distribution will make permittivity value increase. The resulting increase in conductivity associated with ions will give rise to and increased imaginary component and hence complex permittivity and measure capacitance will increase.

In order to investigate the potential of using ID sensors to monitor transesterification reactions a simple sensor was fabricated, Fig. 1. The electrode pattern was created on a printed circuit board using a FR4 substrate. The copper plate thickness was $35 \mu \mathrm{m}$; the width of the track forming the ID fingers was $1.6 \mathrm{~mm}$ and the surface finished by Ormecon (partial chemical tin for ultra-flat pads). The original layout was created by Proteus 7 PCB design software and a number of sensors were produced from a single PCB sheet. The resulting sensor had a $1.5 \mathrm{~cm}^{2}$ effective area and $0.4 \mathrm{~mm}$ gap width between digits. A precision shunt resistor $(40.2 \mathrm{~K} 0.1 \%$ tolerance) was used to sense the circuit current (see Fig. 2).

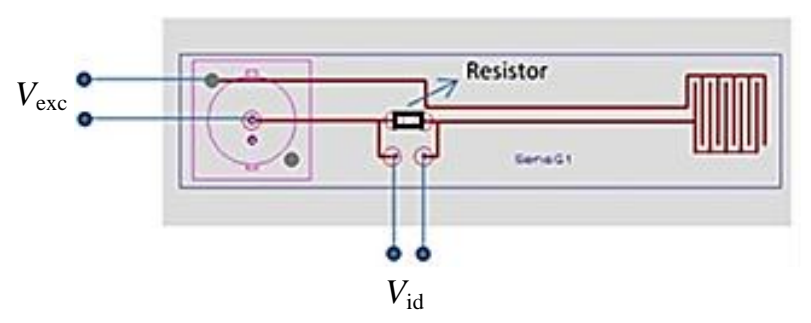

Fig. 2. Interdigital sensor.

The conductive current is dependent on the ion concentration related with dynamic of the process, it can be measured by flowing current flow through the sensor. In order to measure the current along the sensor, the voltage across the shunt resistor was measured:

$$
\begin{aligned}
& V_{\mathrm{exc}}=I_{\mathrm{id}} * Z \\
& V_{\mathrm{id}}=I_{\mathrm{id}} * R_{\mathrm{id}}
\end{aligned}
$$

where $V_{\text {exc }}$ excitation voltage across the sensor, $V_{\text {id }}$ is the sensing voltage across the shunt series resistor $R_{\text {id }}$ and $I_{\text {id }}$ is flowing current across the resistor. The impedance of the sensor:

$$
Z=V_{\mathrm{exc}} / V_{\mathrm{id}} * R_{\mathrm{id}}
$$

The real part and imaginary part of the sensor can be calculated: 


$$
\begin{aligned}
& Z^{\prime}=Z^{*} \operatorname{Cos} \theta \\
& Z^{\prime}=Z^{*} \operatorname{Sin} \theta
\end{aligned}
$$

The voltage magnitude of $V_{\text {id }}$ and voltage phase between $V_{\text {exc }}$ and $V_{\text {id }}$ is measured.

\section{EXPERIMENTAL INVESTIGATION}

\section{A. Method}

A small laboratory scale $(<100 \mathrm{ml})$ batch reaction facility was established using a $100 \mathrm{~mL}$ borosilicate flask, mechanical agitation by magnetic stirrer and temperature control via a thermostatically controlled hot plate.

The reactants comprised of methanol $(99.9 \%), 1 \% \mathrm{KOH}$ (85\%) catalyst and commercially available food grade sunflower oil. At the start of each experiment $60 \mathrm{~mL}$ of sunflower triglyceride was decanted into the clean flask and heated to the reaction temperature of $50^{\circ} \mathrm{C}$. The methoxide was injected at a controlled rate into the bottom of the flask using a metered dosing pump in order to achieve a methanol to oil molar ratio of $6: 1$. The rate of methanol injection was $300 \mathrm{ml} / \mathrm{hr}$ and the injection period was $90 \mathrm{~s}$.

The ID sensor was immersed in the feedstock and exited with $5 \mathrm{Vpp} 15 \mathrm{kHz}$ AC sinusoidal waveform. The excitation signal was selected so as to be compatible with implementation within existing FPGA technologies and as such will be suitable for future commercial development. The resulting current waveform was obtained from the potential difference across the shunt resistor. Both waveforms were digitised at 250k samples per second using a National Instruments ELVIS II used in conjunction with bespoke software. The software captured the raw data, applied filtering and output results at 10 second intervals with the impedance averaged over the preceding 10 second period. This reduced the level of noise on the impedance results and the 10s output period produced data fast enough to capture the details of the transesterification process.

The sensor was immersed in feedstock and data captured for a period of 60 s prior to the start of methoxide injection. This data was subsequently analyzed to detect any unwanted sensor drift and/or any influence by the magnetic stirrer.

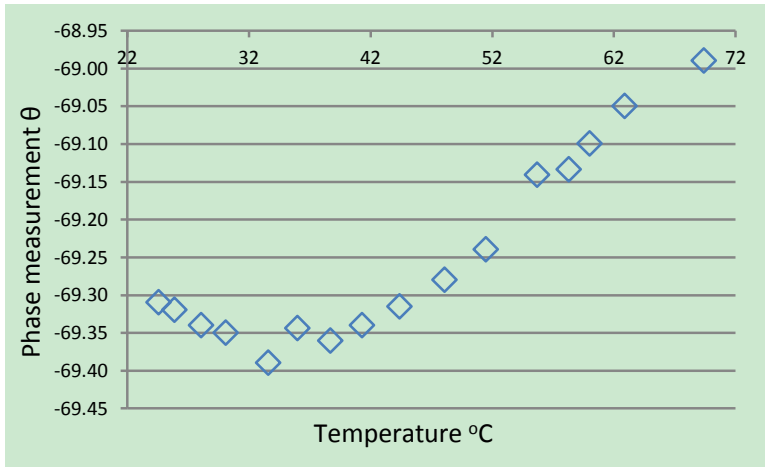

Fig. 3. Phase measurement of sunflower oil heating up temperature $24-70^{\circ} \mathrm{C}$.

\section{B. Result and Discussions}

Experiments were undertaken to investigate the performance of the sensor with regard to the effects of temperature change. To cover the typical range of temperatures used during the transesterification reaction $\left(20^{\circ} \mathrm{C}-70^{\circ} \mathrm{C}\right)$ the sensor and a thermocouple were immersed in $80 \mathrm{ml}$ of sunflower oil. The oil was then heated via a hot plate and mixed by rotating magnetic stirrer.

Fig. 3 illustrates the variation of phase angle that occurred, it can be seen that there is a very small change in phase angle (approx. $0.4^{\circ}$ ) over the temperature range investigated. There was also a small increase $(0.2 \mathrm{mV})$ in the potential difference measured across the shunt resistor as illustrated in Fig. 4.

Fig. 5 can be derived using equation 3 , as can be seen from the graph 5 that capacitance value from $22.4^{\circ} \mathrm{C}-33.6^{\circ} \mathrm{C}$ remains stable around $5.581 \mathrm{pF}$. Increasing of capacitance value can be observed after $33.6^{\circ} \mathrm{C}$ until $69.4^{\circ} \mathrm{C}$ is $0.032 \mathrm{pF}$ which corresponds to a change of approximately $0.5 \%$. There is no visible change in permittivity in low temperature while the changing in higher temperature is not notably high.

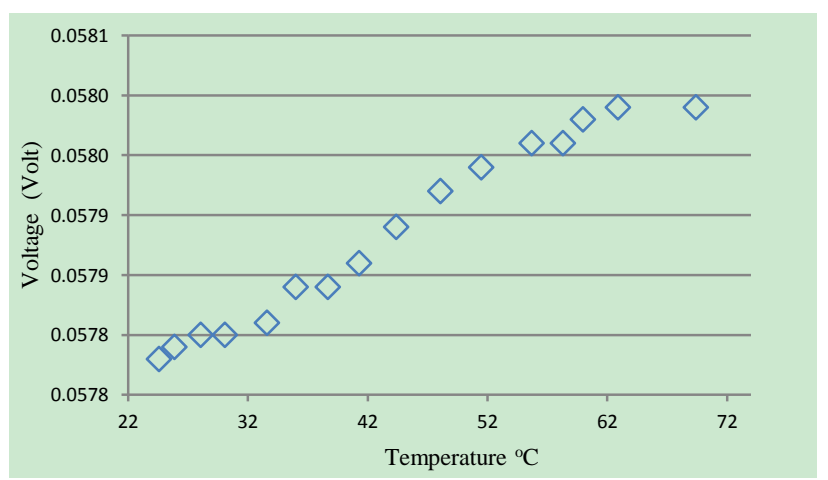

Fig. 4. Voltage response of sunflower oil heating up temperature $24-70^{\circ} \mathrm{C}$.

At the same time, the resistance part has a slight decrease in around $3 \mathrm{k}$ ohm at lower temperature, after $33.6^{\circ} \mathrm{C}$ increase rapidly. Simultaneous changing in impedance parameters has been observed during the heating process.

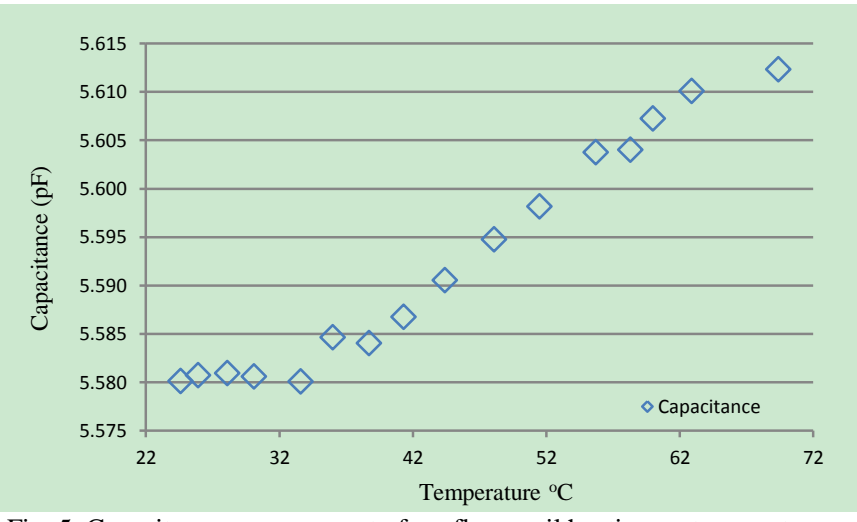

Fig. 5. Capacitance measurement of sunflower oil heating up temperature $24^{\circ} \mathrm{C}-70^{\circ} \mathrm{C}$.

Temperature is well understood to cause increased electrical conductivity, and the conductivity can be expressed [20]:

$$
\sigma=\sigma_{0} * e^{\frac{W}{k \cdot T}}
$$

where $\sigma$ is conductivity of the material, $k$ is the Boltzman constant and $T$ is the temperature and $W$ is the activation energy.

An increase in liquid temperature will cause the liquids viscosity to decrease and this leads to increase in the ions mobility in liquid. Also elevated temperatures may cause an increase in the number of charge carrier available in the liquid due to dissociation of molecules. Since conductivity in 
liquid is dependent factor as in equation (12), increasing liquid temperature lead to increasing liquid conductivity subsequently [21].

It can be seen that capacitance has steady value at lower temperatures and has slight increase at higher temperatures. The slight increase in capacitance value shown Fig. 5 is caused by increasing liquid dielectric constant. Both real part and the imaginary parts increase slightly with temperature, resulting increasing capacitance values. Furthermore, increasing conductivity values due to temperature make the value of dielectric loss increase respectively. This result agrees with other measurement [22].

The impedance components have slight changing during heating from $22.4^{\circ} \mathrm{C}-69.4^{\circ} \mathrm{C}$, the changing of the impedance is mainly caused by activation energy. Also lower mass transfer coefficient has correlation with lower temperature on transesterification biodiesel process [14].

The virgin vegetable oil used for the work described is a predominately non-polar fluid with a low ion concentration. On the other hand, the methoxide is a polar fluid with a high ion concentration. These differences give rise to different electrical properties (conductivity and permittivity) and each individual fluid would be expected generate a significantly different response from the ID sensor.

The virgin vegetable oil used for the work described is a predominately non-polar fluid with a low ion concentration. On the other hand, the methoxide is a polar fluid with a high ion concentration [23]. These differences give rise to different electrical properties (conductivity and permittivity) and each individual fluid would be expected generate a significantly different response from the ID sensor.

As both fluids are immiscible then there is a need to mix the reactants together before the reaction may proceed. Without mixing there is a high mass transfer resistance between the fluids and the transesterification reaction would only proceed as a very slow rate. During mixing it is normal to inject the methoxide into the raw oil and hence the initial sensor response will be based on the electrical properties of the raw oil. With further mixing the sensor response will change to reflect the increased conductivity due to the increased ion concentration associated with the methoxide.

Therefore, based on mass transport phenomena theory, mass transfer resistance exists between two fluids. The progress of mass transfer can be detected by measuring ion transport throughout the oil. The measurement may be conducted from triglyceride phase which has high resistance or methanol phase with high conductivity. Mass transfer resistance influence is clearly feasible in low temperature compare with high temperature [24]. As the vegetable oil has high viscosity in lower temperature, heating the oil during the transesterification process will do a favour to speed up the process by shortening mass transfer control region time.

TABLE I: PERMitTivity VALUE OF SOME VEGETABLE OILS AND

\begin{tabular}{l|c}
\multicolumn{2}{c}{ METHANOL AT $25^{\circ} \mathrm{C}[22]$} \\
\hline \multicolumn{1}{c}{ Material } & Permittivity $\varepsilon$ \\
\hline Rapeesed & 3.08 \\
\hline Sunflower & 3.09 \\
\hline Soybean & 3.04 \\
\hline Corn & 3.13 \\
\hline Methyl ester & 3.32 \\
\hline Methanol & 32.6 \\
\hline Glycerol & 42.5 \\
\hline
\end{tabular}

Recent hypothesis about transesterification process on batch reactor stated the mechanism reaction of transesterification process consist an early stage of mass transfer controlled region followed by kinetically controlled region. Chemical reaction between triglyceride with methanol will occurred after mass transfer start.

During the reaction long chain of triglyceride hydrocarbon molecule will break out become smaller chain diglyceride, monoglyceride and glycerol. The changing of this molecules will be affected how the reactants adsorb the applied electromagnetic.

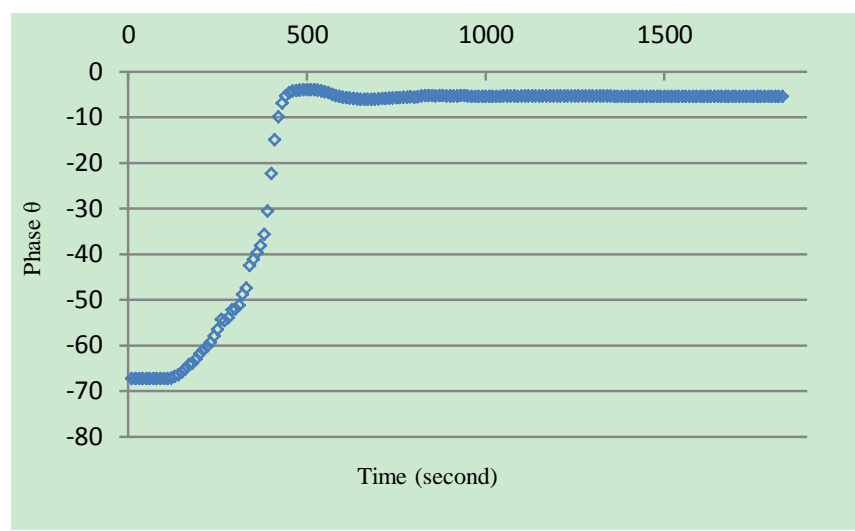

Fig. 6. Phase shift measurement of transesterification process at $40^{\circ} \mathrm{C}$.

Fig. 6 and Fig. 7 are plotting measurement of phase different and voltage response from sunflower biodiesel transesterification process at $40^{\circ} \mathrm{C}$. Data value has been recorded every second and averaging every 10 seconds. The measured $\theta$ remains unchanging during 60 seconds introduced methoxide, and then increase rapidly during in the first 500 seconds. Possible affected parameters on $\theta$ are conductivity $\sigma$ and permittivity $\varepsilon$ or both of them changing simultaneously.

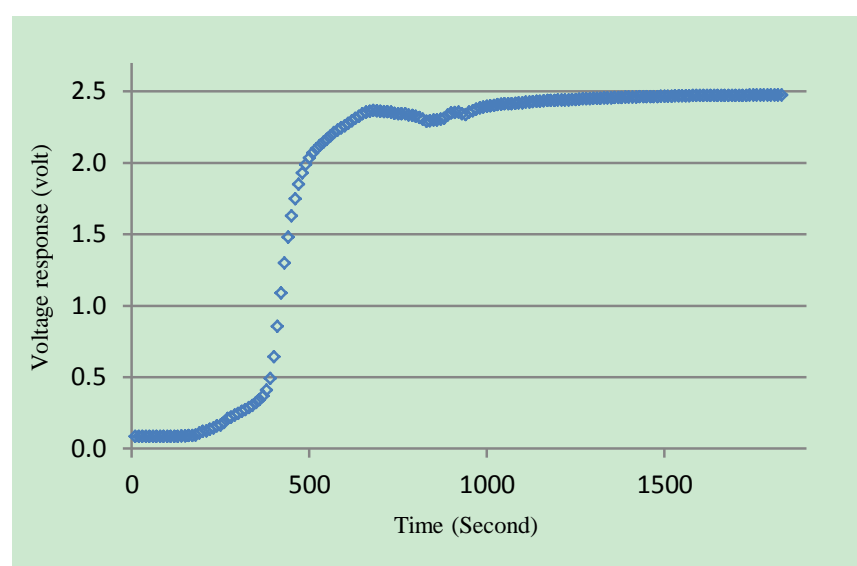

Fig. 7. Voltage respons of transesterification process at $40^{\circ} \mathrm{C}$.

As can be seen from Fig. 8, impedance measurement is plotting against the time process. At early stage of the process reactance has higher value than real part, more than double. This is caused by permittivity value of triglyceride, vegetable oil has small permittivity value. When the methoxide has introduced with continues injection rate of $300 \mathrm{ml} /$ minute and completed in 90 seconds, the reactance line has rapid decline. Since the fluid is a mixture of vegetable oils and methoxide, the permittivity which sense by sensor is total material fluids under the reaction.

Fig. 8 shows that real part of the impedance is lower compare with the imaginary part. Precision shunt resistor 
value has significant influence in moving phase impedance. A shunt resistor $40.2 \mathrm{~K} \Omega 0.1 \%$ tolerance, have been chosen to increase sensitivity on imaginary part of total impedance [25], more over it is to suppress highly conductance sensitivity during introduction of methanol into the vegetable oil.

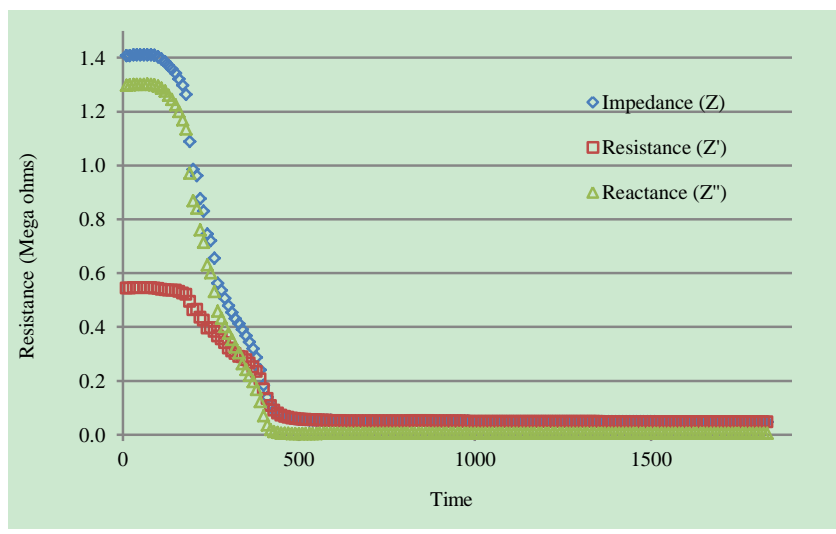

Fig. 8. Impedance measurement of trasesterification process.

Fig. 9 represents simultaneous measurement of resistance (real part) and capacitance (derived from imaginary part) value during sunflower oil transesterification process. As resistance line is measure of ion transport, in this case disperse methanol in to the vegetable oil. Furthermore, the slop of ion distribution is represented mass transfer progress, and this slope is highly affected by droplet size of dispersed methanol and it reduces rapidly with progress of transesterification process [24].

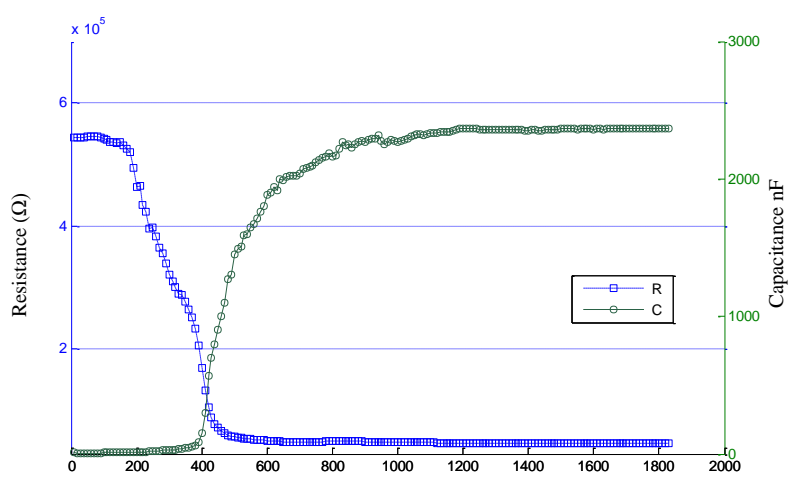

Fig. 9. Resistance and Capacitance measurement during the transesterification process.

The mass transfer resistance is caused by small availability of active specific catalyst surface, which is mainly covered by adsorbed molecules of methanol [26]. It is proven that progress of mass transfer have sigmoid process kinetics which have slow slope in the early stage and rapid in the middle and slowing down line before it reach steady state.

When the ion distribution (mass transfer) nearly reached steady state condition the capacitance value start and has steep increase before it slowing. On the early stage of the transesterification process, the reactance is separated in triglyceride phase and methanol phase. As two phases is not immiscible caused poor diffusion between the phases it has a result in a reaction rate. When methyl esters are formed, it will become a mutual solvent for reactants [9], and boost the reaction as explain by steep increase in capacitance value. When the catalyst and reactance is decrease consumed by the process, the reaction rate has slow before it reached steady state.

Capacitance value of vegetable oil at the beginnings of the process is very low just around $8.18 \mathrm{pF}$, and the value increase when the chemical reaction is begin. The capacitance value is depending on the permittivity of the reactants. Since the permittivity is determined by how the molecules of chemical compounds respond to the applied electromagnetic field, it means any changing in molecular reactants the permittivity value will change.

\section{CONCLUSION}

A batch transesterification reaction of vegetable oils consist two important stages, mass transfer controlled region and kinetically controlled region. Mass transfer stages is important part of the process because overall transesterification process speed is depend on how fast this stage. Slow biodiesel process lead in energy and time inefficiency.

A measurement of biodiesel transesterifications monitoring process by means of impedance measurement has been presented. The suggested impedance measurement technique shows promise of being useful for process monitoring as feedback to determine the progress of the biodiesel reaction. Simultaneous measurement of the resistant and reactant has represent the two stages of transesterification biodiesel reaction which is contain mass transfer control region and kinetically controlled region. The monitoring technique detects the dispersal of methoxide throughout the reacting mixture and changing in permittivity of reactants during the reaction. The graphs shows the process of reducing resistance which is depict the mass transfer following by increasing capacitance and permittivity which is represent the chemical reaction during the reaction, this is consistent with the findings of other researches.

The proposed sensor is very simple to fabricate, has no moving parts and requires relatively simple electronics. The resulting measurement data is very useful for the control of early stages of the transesterification process and the detection of steady state conditions. It may be possible to use the sensor to detect the process steady state and save energy during the process by reducing the speed of the mechanical agitation after complete mixing has been achieved.

\section{REFERENCES}

[1] A. Dermibas, Biodiesel, A realistic fuel alternative for diesel engines, Springer, 2008, p. 67.

[2] A. Dermibas, "Importance of biodiesel as transportation fuel," Energy Policy, vol. 35, pp. 4661-4670, 2007.

[3] F. Ma and M. A. Hanna, "Biodiesel production: a review," Bioresour Technol, vol. 70, pp. 1-15, 1999.

[4] D. Frascari, M. Zuccaro, D. Pinelli, and A. Paglianti, "Optimization of mechanical agitation and evaluation of the mass transfer resistance in the oil transesterification reaction for biodiesel production," Industrial \& Engineering Chemistry Research, pp. 7540-7549, 2009.

[5] G. Knothe, "Rapid monitoring of transesterification and assessing biodiesel fuel quality by near infrared spectroscopy using a fiber optic probe," J. Am Oil Chem. Soc., vol. 76, no. 7, pp. 795-800, 1999.

[6] N. Ellis, F. Guan, T. Chen, and C. Poon, "Monitoring biodiesel production (transesterification) using in situ viscometer," Chem Eng Journal, vol. 138, pp. 200-206, 2008.

[7] M. G. Trevisan, "Monitoramento de reacoes quimicas empregando spectroscopy no infravermelho (Monitoring of chemical reaction with 
infrared spectroscopy)," Campinas, p. 147, Tese (Quimica Analitica), 2009.

[8] L. A. B. de Boni and I. N. Lima da Silva, "Monitoring the transesterification reaction with laser spectroscopy," Fuel Processing Technology, vol. 92, pp. 1001-1006, 2001.

[9] H. Noureddini and D. Zhu, "Kinetics of transesterification of soybean oil," J. Am. Oil Chem. Soc., vol. 74, pp. 1457, 1997.

[10] T. Kai, Y. Mataki, T. Nakazato, and H. Takanashi, "Optimization of reaction conditions of two-step batch operation for biodiesel fuel production using $\mathrm{KOH}$ catalyst," Journal of Chemical Engineering of Japan, vol. 43, no. 1, pp. 90-94, 2010.

[11] M. E. Bambase, N. Nakamura, J. Tanaka, and M. Matsumura, "Kinetics of hydroxide-catalyzed methanolysis of crude sunflower oil for the production of fuel-grademethyl esters," Journal of Chemical Technology and Biotechnology, vol. 82, no. 3, pp. 273-280, March 2007.

[12] D. Frascari, M. Zuccaro, D. Pinelli, and A. Paglianti, "Optimization of mechanical agitation and evaluation of the mass transfer resistance in the oil transesterification reaction for biodiesel production," Industrial \& Engineering Chemistry Research, pp. 7540-7549, 2009.

[13] B. Klofutar, J. Golob, B. Likozar, C. Klofutar, E. Zagar, and I. Poljansek, "The transesterification of rapeseed and waste sunflower oils: Mass-transfer and kinetics in a laboratory batch reactor and in an industrial-scale reactor/separator setup," Bioresource Technology, vol. 101, no. 10, pp. 3333-3344, May 2010.

[14] I. Poljansek and B. Likozar, "Influence of mass transfer and kinetics on biodiesel production process,"Mass Transfer in Multiphase Systems and its Application, ch. 19, InTech, 2011.

[15] M. A. Yunus and S. C. Muhopadhyay, "Planar electromagnetic sensor based estimation of nitrate contamination in water sources using independent component analysis," IEEE Sensors Journal, vol. 12, no. 6, June 2012.

[16] A. R Mohd Sayifudin, K. P. Jayasundera, and S. C. Mukhopadhyay, "A low cost novel sensing system for detection of dangerous marine biotoxins in seafood," Sensor and Actuators B, vol. 137, pp. 67-75, 2009.

[17] S. Laschi and M. Mascini, "Planar electrochemical sensors for biomedical applications," Medical engineering \& physics, vol. 28, no. 10, pp. 934-943, 2006.

[18] S. C. Mukhopadhyay, "Novel planar electromaganetic sensors: modeling and performance evaluation," Sensors, vol. 5, pp. 546-579, 2005.

[19] J. S. Seybold, Introduction to RF propagation, John Wiley \& Sons, New Jersey, 2005

[20] T. Judendorfer, A. Pirker, and M. Muhr, "Conductivity measurements of electrical insulating oils," in Proc. 2011 IEEE International Conference on Dielectric Liquids (ICDL), June 2011, pp. 1-4.
[21] R. Bartnikas, Engineering Dielectrics Volume III Electrical Insulating Liquids, ASTM, Philadelphia, pp. 4-36, 1994.

[22] S. D. Romano and P. A. Sorichetti, Dielectric spectroscopy in biodiesel production and characterization, Springer, 2011

[23] W. Zhou and D. G. B. Boocock, "Phase behavior of the base-catalyzed transesterification of soybean oil," Journal of the American Oil Chemists' Society, vol. 83, no. 12, pp. 1041-1045, 2006.

[24] O. S. Stamenkovic, Z. B. Todorovic, M. L. Lazic, V. B. Veljkovic, and D. U. Skala, "Kinetics of sunflower oil methanolysis at low temperatures," Bioresour. Technol., vol. 99, no. 5, pp. 1131-1140, 2008.

[25] S. C. Mukhopadhyay, "Novel planar electromaganetic sensors: modeling and performance evaluation," Sensors, vol. 5, pp. 546-579, 2005.

[26] V. B. Veljkovic, O. S. Stamenkovic, Z. B. Todorovic, M. L. Lazic, and D. U. Skala, "Kinetics of sunflower oil methanolysis catalyzed by calcium oxide," Fuel, vol. 88, no. 9, pp. 1554-1562, September 2009.

Tri Rachmanto is currently a Ph.D. research student at School of Engineering and Maritime Operation at Liverpool John Moores University and he is also a member of staff of Mechanical Engineering Department at Mataram University, Indonesia. He received the bachelor's degree in mechanical engineering from Brawijaya University, Malang, East Java, Indonesia and master of science from Liverpool John Moores University. His research interest in mechatronics, measurement, sensors, and renewable energy.

David Allanson is currently a principal lecturer in the School of Engineering Technology and Maritime Operations at Liverpool John Moores University. He has undertaken research into the areas of control and optimization, tribology and applied fluid mechanics.

Christian Matthews is currently a principal lecturer in the School of Engineering Technology and Maritime Operations at Liverpool John Moores University. He received his $\mathrm{PhD}$ from the University of Liverpool. His research interest in dynamic modelling, system identification, control and simulation.

I. Jenkinson is the director of the School of Engineering Technology and Maritime Operations at Liverpool John Moores University. His research is in the application of artificial intelligence to problems in engineering particularly in the area of risk and reliability. 